\title{
崇明东滩越冬鸟类在养殖塘的空间分布
}

\author{
赵锦霞 ${ }^{1, *}$, 刘 昊 ${ }^{2}$, 张利权 ${ }^{1}$ \\ （1. 华东师范大学 河口海岸学国家重点实验室, 上海 200062； 2. 绵阳师范学院, 四川 绵阳 621000)
}

\begin{abstract}
摘要: 鸟类对空间的利用直接反映对栖息地的选择。通过对崇明东滩养殖塘越冬鸟类群落调查, 运用空间自 相关检验、空间插值分析和景观格局分析, 研究越冬鸟类在养殖塘人工湿地的空间分布格局。结果显示: 雁鸭类 和彻㗜类在养殖塘分布特征显著不同。雁鸭类呈现显著的空间自相关, 为聚集分布, 且丰富度和多度分布较为一 致; 而彻捅类在养殖塘以随机分布为主, 丰富度显示一定的聚集分布。养殖塘已经成为崇明东滩越冬鸟类重要的 栖息地, 不同生态类群栖息地选择存在差异: 芦苇植被发育好, 水域面积较小且水深较深, 不同斑块以聚集为特 征的养殖塘是雁鸭类的适宜生境; 鸿璚类则偏好一定芦苇植被、水域面积大且水深较浅的养殖塘。因此在保护区 土地利用和管理时应考虑不同生态类群对栖息地选择的差异。
\end{abstract}

关键词: 越冬鸟类; 养殖塘; 空间统计学; 空间分布; 崇明东滩

中图分类号: Q958.1; X503.224 文献标识码: A 文章编号: 0254-5853(2008)02-0212-07

\section{Spatial Patterns for the Distribution of Winter Waterbirds in the Aquaculture Ponds of Chongming Dongtan, Shanghai}

\author{
ZHAO Jin-xia ${ }^{1, *}$, LIU Hao ${ }^{2}$, ZHANG Li-quan ${ }^{1}$ \\ (1. State Key Laboratory of Estuarine and Coastal Research, East China Normal University, Shanghai 200062, China; \\ 2. Sichuan Mianyang Normal University, Sichuan Mianyang 621000, China)
}

\begin{abstract}
The spatial utility pattern of birds reflects their selection of habitats. Based on field surveys, spatial statistics and landscape pattern analyses, we investigated the distribution pattern of winter waterbirds in the aquaculture ponds of Chongming Dongtan, Shanghai. The results showed that ducks had a different pattern from that of waders. The distribution pattern of ducks revealed a significantly positive autocorrelation and clustered distribution, while that of waders showed a non-autocorrelation and random distribution. As a supplementary habitat, the aquaculture ponds play an important role for winter waterbirds. There are, however, differences in selecting habitats among groups of winter waterbirds. Ducks prefer ponds with well-developed reed vegetation, a relatively smaller water area and deeper water, while waders favor larger water areas and shallower water. The requirement of habitats for different groups of winter waterbirds should be taken into account when planning land use and managing a natural reserve.
\end{abstract}

Key words: Winter waterbirds; Aquaculture ponds; Spatial statistics; Spatial distribution; Chongming Dongtan

湿地是世界上生产力最高、生物多样性最丰富 的生态系统之一，是水鸟赖以生存的主要生境。然 而，湿地也是受人类破坏和威胁最严重的生态系统 (Chen, 1995)。在全球自然湿地不断丧失和退化 的情况下, 人工湿地的功能和作用越来越受到生态 学者的关注 (Ge et al, 2006)。人工湿地能否替代自 然湿地成为水鸟的适宜生境是保护生物学研究的 一个重要问题 (Yang, 2002)。
崇明东滩国家级鸟类自然保护区地处长江入海 口, 位于东亚一澳大利亚鸟类迁徙路线的中部, 其 特殊的地理位置、良好的生态环境及丰富的食物资 源吸引了大量的迁徙鸟类在此停息、越冬 (Minton, 1982)。然而, 随着社会经济的快速发展, 导致崇明 东滩大量的自然滩涂湿地被围垦利用, 其中很大一 部分转变为养殖塘、稻田和水库等人工湿地 (Sun \& Zhao, 1996; Gao \& Zhao, 2006)。一些研究认为

收稿日期：2007-12-13; 接受日期：2008-01-28

基金项目：上海市科委重大科技攻关项目(06dz12302); 国家科技支撑计划项目（2006BAC01A14）

*通讯作者 (Corresponding author), E-mail: zjx2369@sohu.com 
养殖塘等人工湿地无法取代自然滩涂 (Ma et al, 2004), 也有学者认为养殖塘作为鸟类栖息地的补 充可以发挥重要的生态作用。人工湿地作为自然滩 涂的补充, 在生物保育方面发挥了重要作用 (Ge et al, 2006)。

近年来, 生态学家们开始关注在景观尺度上的 格局与过程对生态系统如生物多样性、斑块利用、 经济和生态的可持续发展等的潜在影响。在鸟类生 态学研究中, 一些学者探讨了在景观尺度上鸟类的 斑块利用以及在此基础上的预测和管理技术。这些 研究把生物数据和环境因子与较大尺度空间数据 结合, 研究不同尺度下生物与景观异质性的相互关 系, 探讨了景观格局对鸟类物种丰富度、多度和湿 地景观中斑块使用的重要性, 以期为湿地保护与管 理以及决策提供参考 (Wang \& Chen, 2004; Turner, 2006)。

为研究崇明东滩养殖塘等人工湿地的景观格局 对鸟类物种丰富度、多度和斑块利用的影响, 本文 从景观生态学的角度, 以野外调查为基础, 应用空 间统计学, 研究越冬鸟类在崇明东滩养殖塘的空间 分布特征, 旨在全面评价人工湿地在该地区水鸟保 护中的价值和作用, 为崇明东滩岛类保护区的管理
和决策提供科学依据。

\section{1 研究方法}

\section{1 研究区域}

崇明东滩位于长江入海口, 上海崇明岛的东 端, 是上海滩涂湿地的主要分布区域之一。自 20 世纪 60 年代以来, 东滩的围垦面积累计已经达到 约 $152 \mathrm{~km}^{2}$ 。崇明东滩鸟类自然保护区, 其范围在 98 大堤以东潮间带滩涂和周围水域, 总面积为 246 $\mathrm{km} 2$, 包括吴淞高程 $0 \mathrm{~m}$ 线以上的滩涂面积 $100 \mathrm{~km}^{2}$ 和 $0 \mathrm{~m}$ 线以外宽度 $3000 \mathrm{~m}$ 的水域 $146 \mathrm{~km}^{2}$ 。从湿地 保护和土地合理利用的意向出发, 98 大堤和 92 大 堤之间的土地作为自然保护的缓冲地带, 发展为养 殖塘人工湿地, 位于北纬 $31^{\circ} 33^{\prime} 16^{\prime \prime} 、 31^{\circ} 28$ ' 48" , 东经 $121^{\circ} 57^{\prime} 13^{\prime \prime} 、 121^{\circ} 54^{\prime} 37^{\prime \prime}$ 之间, 面积约 $20 \mathrm{~km}^{2}$ (图 1)。本区域东临东滩鸟类自然保 护区, 西临农场, 已经成为越冬鸟类的重要栖息地, 也是本文的研究区域。东滩养殖塘人工湿地可分为 $A 、 B 、 C$ 三个区域。A 区为 92 大堤到 98 大堤间南 部的区域; B 区为北部养殖塘区域和湿地公园; C 区为 92 大堤以西的养殖塘区域（图 1)。

该地区属于东部亚热带季风气候: 夏季多从太
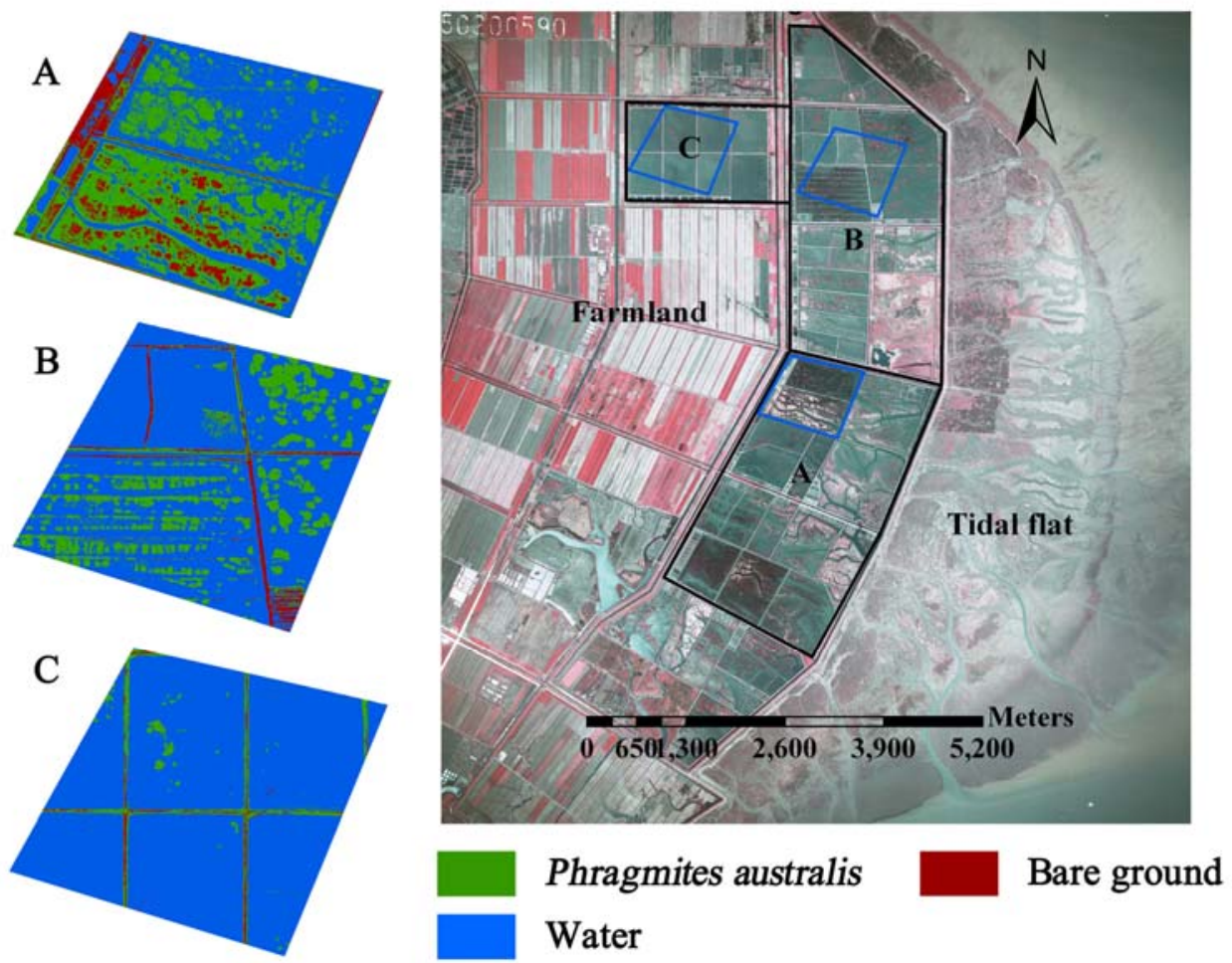

图 1 研究区域位置、养殖塘人工湿地的 ABC 区和各区典型的土地覆盖状况

Fig. 1 The location of study area, three divisions of aquaculture wetlands and their typical landcover 
平洋吹来暖湿气团, 雨量丰富, 温和湿润; 四季分 明。年均日照时数 $2138 \mathrm{~h}$, 太阳总辐射量为 4300$4600 \mathrm{MJ} / \mathrm{m}^{2}$, 年均气温 $15.3^{\circ} \mathrm{C}$, 最热月为 $7-8$ 月, 月平均气温 $26.8-26.9^{\circ} \mathrm{C}$, 最冷月为 $1-2$ 月, 月平 均气温在 $3.0-3.9^{\circ} \mathrm{C}$ 。全年平均无霜期为 320 天左 右, 年平均降雨量 $1022 \mathrm{~mm}$, 相对湿度 $82 \%$ 。

土地利用状况信息源于 2005 年 5 月崇明岛的航 空遥感彩红外影像, 其分辨率为 $0.8 \mathrm{~m}$ 。影像在 ArcGIS9.2 下进行地理配准、几何纠正和拼接, 土 地利用类型采用人工目视判读解译。人工目视判读 解译主要根据影像地物的几何特征、色彩、结构与 纹理、地理位置等综合信息, 初步解译的土地利用 类型, 再经过野外实地抽样调查验证 (Dang et al, 2003; Huang et al, 2005)。土地利用类型分为 8 个 类型: 芦苇斑块、水域、裸露地面、沟渠、道路、 旱田、水田和堤坝; 其中养殖塘区以芦苇斑块、水 域和裸露地面为主要覆盖类型, 各区域的典型土地 覆盖状况见图 1。

\section{2 乌类调查}

越冬鸟类调查是在 2004 年 11 月至次年 2 月和 2005 年 11 月至次年 1 月进行。两个冬季共 7 次, 每次在两天内完成调查。选择在每月大潮前后的晴 好天气进行调查, 且每天的调查尽量在最高潮位前 后两小时内完成。调查时, 两人一组用 8 倍双筒和 20-60 倍单筒, 样线法沿养殖塘埂行进, 两人对观 察结果达成共识后, 记下水鸟数量和种类, 头顶飞 过水鸟不做记录。对不能精确识别种类的, 根据外 形归为未识别雁鸭类或未识别鸿璚类, 并以 10 为 单位计数, 纳入多度的计算, 不参与水鸟丰富度的 计算。不易区分的鸟类, 如青脚㛚(Tringa nebularia) 和小青脚䂆⿹ (Tringa guttifer)、扇尾沙雉 (Gallinago gallinago) 和针尾沙雉 (Gallinago stenura), 则分 别合记为青脚㦷 (Tringa nebularia) 和沙雉

\section{(Gallinago sp.)。}

对所调查鸟类数据进行整理和统计, 由于养殖 塘越冬水鸟以雁鸭类和鸥预类为主要类群, 选择丰 富度和多度为群落的主要描述参数。共获得雁鸭类

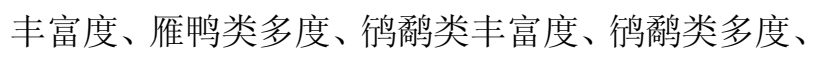
水鸟群落丰富度和水鸟群落多度 6 个参数。其中只 在一个冬季被记录且遇见次数小于 2 次的种类不计 入丰富度统计, 但记入多度统计。数据的统计分析 主要在 SPSS11.0 中进行。

\section{3 空间自相关检验和插值分析}

将获得的鸟类参数及其空间属性输入 ArcGIS9.2 中, 首先进行各参数的 Moran I 空间自相 关检验, 验证鸟类分布的空间自相关性。Moran I 指数的取值一般在- $1-1$ 之间，等于 0 表示不相关; $0-1$ 则表示正相关; $-1-0$ 表示负相关; Z 值是 Moran I 的标准化统计量检验, $\mathrm{Z}$ 值为正且显著时, 表明存在正相关, 相似观测值趋于空间聚集; $\mathrm{Z}$ 值 为负且显著时, 表明存在负的空间自相关, 相似的 观测值趋于分散分布; $\mathrm{Z}$ 值为 0 时, 观测值呈独立 随机分布。

鸟类参数中, 彻璚类多度由于空间不相关, 将

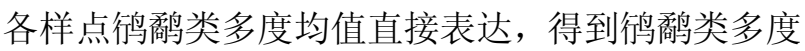
的观测值图; 具有空间自相关特征的 5 个参数在 ArcGIS9.2 中进行空间插值。利用 ArcGIS9.2 中 Spatial Analyst Tools 下 Interpolation 模块的 Kriging 工具, 采用普通克里格插值法 (ordinary Kriging), 生成各鸟类参数的插值结果和变异图。通过多次拟 合比较和分析, 发现球状模型和 12 个点的搜索半 径可以较好地描述丰富度的空间分布状况, 而线形 模型和 12 个点的搜索半径可以较好地描述多度的 空间分布状况, 将最佳设定条件下所得的分布图作 为最终结果(Wu, 2000; Wu et al, 2001; Xu, 2006)。

\section{4 景观格局分析}

按照行璚类和雁鸭类分布图中的高值区域, 提 取相应区域的土地覆盖信息, 进行景观格局分析。 雁鸭类提取了多度大于 300 的两个斑块和 B、C 区 域丰富度大于 4 的两个斑块（图 2a 和 b), 共 4 个 样方。鸭䂆类提取了丰富度大于 4 的两个斑块, 而 多度则按调查数据, 取多度大于 38 的 B、C 区域的 3 个养殖塘区进行景观因子计算 (图 2c 和 d), 共 5 个样方。

共选取景观因子 11 个 (表 3), 其中斑块类型数 反映养殖塘斑块组成; 芦苇斑块密度、水域斑块面 积比、芦苇斑块面积比、最大水域斑块面积比、最 大芦苇斑块面积比、平均芦苇斑块面积、平均水域 斑块面积从不同角度定量比表达了养殖塘主要斑 块类型的面积和比例; 芦苇斑块最近相邻距离标准 差 (Standard Deviation for Euclidean Nearest Neighbor Distance, 即 ENN_SD)表示芦苇斑块的分 散程度, 其值越小表示分散程度越低。区域所有斑 块相似邻接百分比 (Percentage of Like Adjacencies, 即 PLADJ) 是计算区域内斑块的聚集程度， $0 \leqslant$ PLADJ $\leqslant 100$, 其值越小, 表示分散程度越大, 
聚集程度越低。景观因子中处理水深为实测值的平 均值, 其余参数均在 Fragstats3.3 中计算。

\section{2 结 果}

\section{1 崇明东滩养殖塘区越冬鸟类群落状况}

本研究共记录到水鸟 51 种 (包括不计入丰富度 的种类)，31572 只。其中雁鸭类 10 种， 21356 只 (67.64\%); 彻劀类 12 种, 4683 只 (14.83\%); 其 他水鸟 [鹭类、鸥类、小鸲鸣(Tachybaptus ruficolli)]14 种, 5533 只 $(17.53 \%)$ 。鸟类群落参数统计见表 1 。

\section{2 越冬鸟类群落的空间自相关性}

利用 Moran I 对水鸟群落分布的空间自相关进 行检验发现, 雁鸭类在养殖塘的分布存在显著的正 相关, 表现为聚集明显。行璚类丰富度呈正相关, 但聚集不明显; 彻璚类多度则不相关, 表现为随机 分布。从整个鸟类群落看, 由于雁鸭类种类数量占 较大比例, 因此整个群落也为正相关, 表现出聚集 分布 (表 2)。

\section{3 越冬鸟类在养殖塘的空间分布}

2.3.1 雁鸭类的分布状况 从雁鸭类的丰富度和 多度分布图来看, 雁鸭类的种类和数量分布存在高 度相似（图 $2 \mathrm{a}$ 和 $\mathrm{b}$ )。最高值都出现在 $\mathrm{A}$ 区域, 整
个 A 区域的雁鸭类的丰富度均较高, 而多度也呈现 了高值斑块。在 $\mathrm{B}$ 和 C 区域, 丰富度和多度普遍较 低, 但是均有斑块状分布, 丰富度更为明显。整个 研究区域内, 丰富度大于 5 的区域面积约为 426.7 $\mathrm{hm}^{2}$, 多度大于 300 的区域面积约为 $279.1 \mathrm{hm}^{2}$ 。养 殖塘, 尤其是 $A$ 区域, 是雁鸭类的重要越冬栖息地。

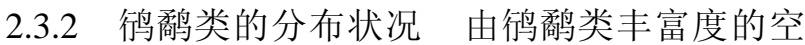
间插值分布图 (图 2c), 可知行濄类丰富度总体聚 集不明显，在 A 区域有行䴔类丰富度的相对高值 区; 另外在 C 区域也有小斑块高分布，丰富度插值 大于 4 的区域面积约为 $239.4 \mathrm{hm}^{2}$ 。行劀多度为随机 分布, 由图 $2 \mathrm{~d}$ 可知微䴔类在整个养殖区数量均较 低，仅 B 和 C 区域有小面积的高值分布（图 2d）。 行䂆岛类多度随机分布和丰富度的不明显聚集，说明 彻璚类在 B 和 C 区域的利用率相对较多, 而 A 区 域不是鸭璚类的集中场所。因此，雁鸭类和彻璚类 利用养殖塘人工湿地作为栖息地差异也很大。

2.3.3 越冬鸟类群落整体分布特征 由于雁鸭类 在种类和数量上的优势和行璚类随机分布的特征, 使得鸟类群落在养殖塘的 A、B 和 C 区都有分布， 局部聚集的分布状况（图 2e 和 $\mathrm{f}$ )，即整个养殖塘 区均有分布，但仅在 A 区域和 B 与 C 区域的零星

表 1 崇明东滩养殖塘越冬水鸟群落丰富度和多度统计

Tab. 1 Summary of variables of winter waterbirds in the aquaculture ponds of Chongming Dongtan

\begin{tabular}{lcc}
\hline 水鸟参数 Waterbird variables & 均值 \pm 标准差 Mean $\pm S D$ & 值范围 Range \\
\hline 雁鸭类丰富度 Ducks richness & $3 \pm 2.61$ & $0-9$ \\
多度 Ducks abundance & $124 \pm 222.86$ & $0-920$ \\
鸻璚类丰富度 Waders richness & $4 \pm 1.65$ & $1-7$ \\
多度 Waders abundance & $26 \pm 42.53$ & $1-21$ \\
群落丰富度 Community richness & $13 \pm 5.34$ & $5-25$ \\
多度 Community abundance & $183 \pm 240.12$ & $5-1054$ \\
\hline$n=28$. & &
\end{tabular}

表 2 崇明东滩养殖塘越冬水鸟群落自相关检验结果

Tab.2 Results of Moran $I$ test on variables of winter waterbirds in the aqua culture ponds of Chongming Dongtan

\begin{tabular}{cccl}
\hline 水鸟参数 Waterbird variables & Moran I & Z-score & 自相关性 Autocorrelation \\
\hline 雁鸭类丰富度 Ducks richness & 0.184 & 4.712 & Clustered, 聚集明显 \\
多度 Ducks abundance & 0.110 & 3.575 & Clustered, 聚集明显 \\
行柕类丰富度 Waders richness & 0.040 & 1.644 & Somewhat Clustered, 稍许聚集, 但有随机因素 \\
多度 Waders abundance & -0.028 & 0.237 & Random, 既不聚集也不散布, 随机分布 \\
群落总丰富度 Community richness & 0.167 & 4.380 & Clustered, 聚集明显 \\
总多度 Community abundance & 0.082 & 2.873 & Clustered, 聚集明显 \\
\hline
\end{tabular}

$n=28, \quad P=0.01$ 

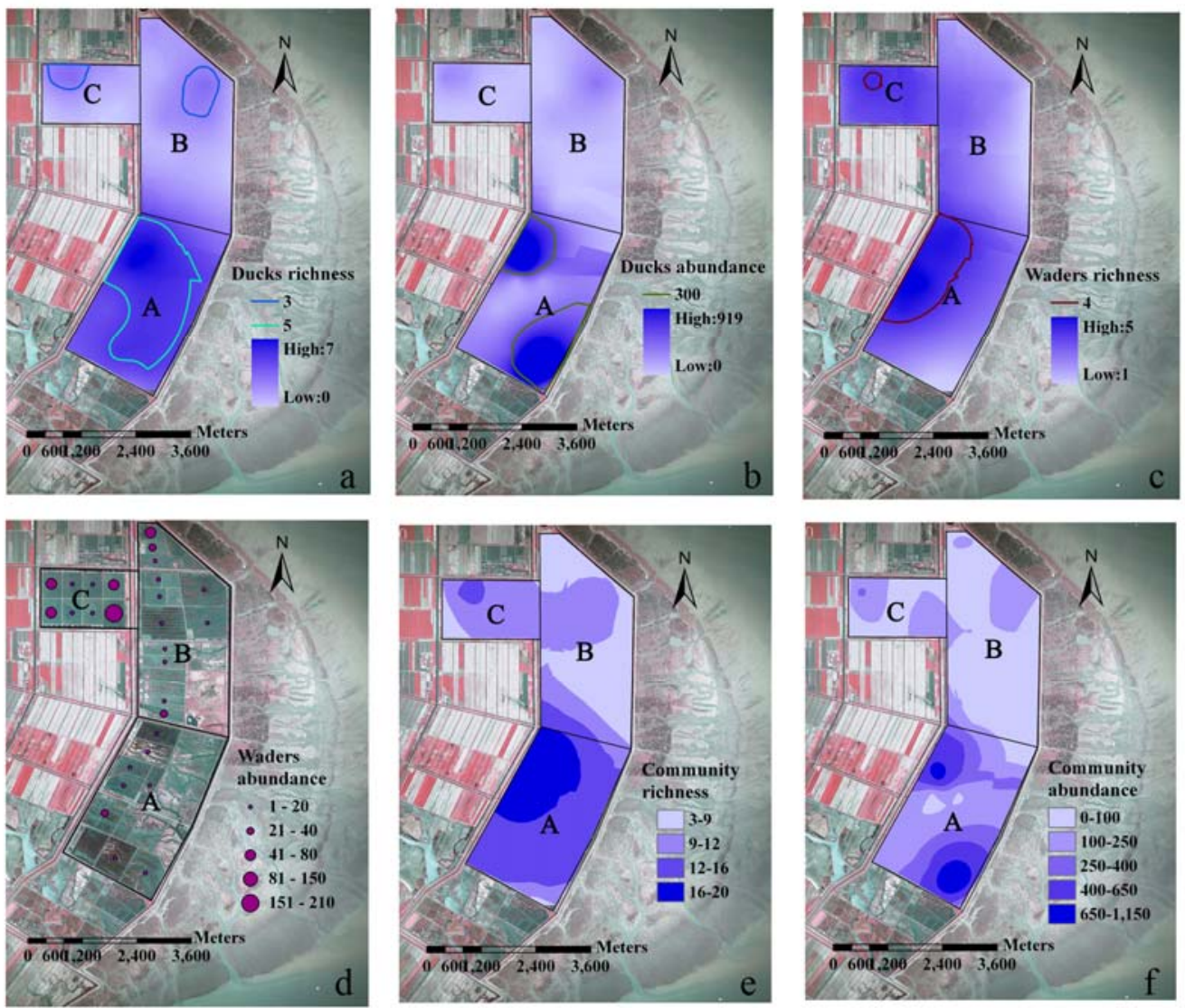

图 2 越冬鸟类在崇明东滩养殖塘分布图

Fig. 2 The spatial distribution of winter waterbirds in the aquaculture ponds of Chongming Dongtan

区域为高值区。综合雁鸭类和鸻憰类参数的分布与 群落整体分布图对比可以看出, A 区域仍然是重要 的丰富度和多度高值区; 而 $\mathrm{B}$ 区域零星斑块和 C 区 域的相对高值区主要是彻颜类的分布区, 是彻敄类 相对聚集的地方。

\section{3 讨 论}

\section{1 雁鸭类的分布与栖息地状况}

鸟类的空间分布一方面可以说明其种内或种间 关系, 另一方面则说明鸟类对栖息地的选择和利用 (Sun, 2001)。雁鸭类在 A 区域的高度聚集, 说明 A 区域是雁鸭类的适宜生境。Ge et al (2006)研究发 现, 雁鸭类越冬鸟类的多个指数与养殖塘植被盖 度、水位和水域面积比例有关。对雁鸭类多度大于 300 的区域和 B 与 C 区域丰富度在 3-4 之间的区 域进行提取, 并计算景观指数 (表 3) 发现, 雁鸭 类适宜区域以芦苇斑块数量多, 面积比例大, 最大 芦苇斑块面积大为特征, 而水域面积则相对比例较 小, 开阔连续水域面积较小; 另外从 ENN_SD 和
PLADJ 指数可以看出, 适宜区域同一种类斑块呈现 聚集分布，而不同斑块组合分布也呈现聚集性。因 此, 由初步的景观因子计算可知芦苇植被发育较 好, 水域面积相对较小且水位较深, 并且不同斑块 以聚集为特征的养殖塘是雁鸭类的适宜生境。

结合文献和实地考察可以发现, 景观尺度上发 育良好的芦苇斑块提高了养殖塘的景观格局多样 性, 同时芦苇斑块也是良好的隐蔽场所, 干扰相对 较小并有利于雁鸭类隐蔽。

\section{2 衍憰类的分布和栖息地状况}

行䂆岛类的随机分布, 可能是两种栖息地状况导 致的结果: 一方面, 养殖塘资源丰富, 适宜性高,

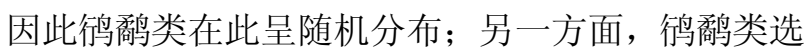
择的栖息地养殖塘呈随机分布, 因而彻鹝类也为随 机分布 (Sun, 2001)。观察发现, 养殖塘主要是行 鹬类在大堤外大潮时的临时停歇地, 作为临时停歇 地, 养殖塘的食物资源相对丰富。另外养殖塘运营 时水位有所变化, 即 12 月到次年 2 月逐渐减小; 而同一时期不同养殖塘的水位又有所不同, 彻敄类 
可停歇在水位较浅的水域, 因此彻鸰类多度和丰富 度随养殖塘水位空间变化而变化 (Liu, 2006)。

Ge et al（2006）研究认为行捅类多度与水面积 呈正相关, 而丰富度和多度则与水位呈负相关, 即 彻谲类的栖息特征仍与在自然湿地类似。因此芦苇 面积比例大, 水位较深的养殖塘区不适宜鸭敄类的 栖息(Zhong et al, 2006)。养殖塘景观格局指数分析 的结果表明 (表 4), 鸭魰类分布区域的斑块类型数 较少, 芦苇斑块密度和面积比例均较小; 而水域面 积比例较大, 且具有较大面积的开阔水域; 不同斑 块组合分布也呈现聚集性, 芦苇斑块的聚集程度小 于雁鸭类分布区, 即斑块间距离相对较大。所以彻
䂆鸟类更偏好具有一定芦苇植被、水域面积相对较大 且水位较浅的养殖塘。实地考察过程中发现, 养殖 塘内的裸露地面周边, 即养殖塘地形造成的浅水区 域较容易发现行毅类。

\section{3 对水鸟保护的建议}

以上研究结果表明, 养殖塘人工湿地已成为东 滩水鸟越冬的重要生境。为更好发挥各种类型湿地 在崇明东滩地区水鸟保护中的作用，提出以下保护 和管理建议: (1)越冬水鸟在东滩人工湿地的分布受 养殖塘生境特征影响, 但不同类群的水鸟对生境特 征的反应有很大差异。应从景观尺度对整个养殖塘 区进行生境管理，提高生境多样性; 依据保护对象

表 3 崇明东滩养殖塘雁鸭类生境景观格局指数

Tab. 3 Landscape metrics for habitat of ducks in the aquaculture ponds of Chongming Dongtan

\begin{tabular}{|c|c|c|c|c|}
\hline 样方 Samples & 1 & 2 & 3 & 4 \\
\hline 斑块类型数（个） Numbers of patch types & 6 & 6 & 6 & 7 \\
\hline 芦苇斑块密度 $\left(\right.$ 个 $\left./ \mathrm{hm}^{2}\right)$ Density of reed patches(per $\left.\mathrm{hm}^{2}\right)$ & 1.29 & 2.04 & 2.35 & 2.40 \\
\hline 芦苇斑块面积比 Percentage of reed patches & 14.33 & 25.33 & 35.45 & 40.14 \\
\hline 水域斑块面积比 Percentage of open water & 82.52 & 72.03 & 50.44 & 51.87 \\
\hline 最大芦苇斑块面积比 Percentage of the largest reed patch & 7.09 & 4.06 & 21.62 & 8.09 \\
\hline 最大水域斑块面积比 Percentage of the largest water area & 45.32 & 68.59 & 30.04 & 47.15 \\
\hline 平均芦苇斑块面积 $/ \mathrm{hm}^{2}$ Average area of reed patch per $\mathrm{hm}^{2}$ & 0.11 & 0.12 & 0.15 & 0.17 \\
\hline 平均水域斑块面积 $/ \mathrm{hm}^{2}$ Average area of water area per $\mathrm{hm}^{2}$ & 1.02 & 3.02 & 0.41 & 0.47 \\
\hline 芦苇斑块最近相邻距离标准差 ENN_SD & 9.93 & 7.57 & 5.31 & 5.20 \\
\hline 所有斑块相似邻接百分比（\%） PLADJ & 87.98 & 83.25 & 71.53 & 73.34 \\
\hline 平均水深 $(\mathrm{m})$ Average water depth (m) & 0.135 & 0.046 & 0.131 & 0.200 \\
\hline
\end{tabular}

ENN_SD: Standard Deviation for Euclidean Nearest Neighbor Distance; PLADJ: Percentage of Like Adjacencies.

表 4 崇明东滩养殖塘衍鵤类生境景观格局指数

Tab. 4 Landscape metrics for habitat of waders in the aquaculture ponds of Chongming Dongtan

\begin{tabular}{|c|c|c|c|c|c|}
\hline 样方 Samples & 1 & 2 & 3 & 4 & 5 \\
\hline 斑块类型数 Numbers of patch types & 2 & 6 & 5 & 6 & 5 \\
\hline 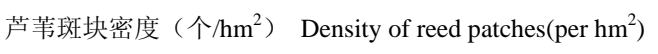 & 1.23 & 2.96 & 1.18 & 1.01 & 3.29 \\
\hline 芦苇斑块面积比 Percentage of reed patches & 5.66 & 25.72 & 10.55 & 4.96 & 21.34 \\
\hline 水域斑块面积比 Percentage of open water & 94.34 & 62.03 & 85.79 & 78.41 & 76.13 \\
\hline 最大芦苇斑块面积比 Percentage of the largest reed patch & 2.18 & 10.84 & 5.42 & 1.15 & 6.32 \\
\hline 最大水域斑块面积比 Percentage of the largest water area & 93.95 & 28.13 & 41.43 & 44.16 & 72.42 \\
\hline 平均芦苇斑块面积 $/ \mathrm{hm}^{2}$ Average area of reed patch per hm² & 0.05 & 0.09 & 0.09 & 0.05 & 0.06 \\
\hline 平均水域斑块面积 $/ \mathrm{hm}^{2}$ Average area of water area per hm² & 2.16 & 0.90 & 1.80 & 5.52 & 1.22 \\
\hline 芦苇斑块最近相邻距离标准差 ENN_SD & 38.01 & 5.91 & 11.20 & 22.22 & 5.15 \\
\hline 所有斑块相似邻接百分比 PLADJ & 95.22 & 74.34 & 89.96 & 89.71 & 80.48 \\
\hline 平均水深(m) Average water depth (m) & 0.13 & 0.138 & 0.122 & 0.130 & 0.07 \\
\hline
\end{tabular}

ENN_SD: Standard Deviation for Euclidean Nearest Neighbor Distance; PLADJ: Percentage of Like Adjacencies. 
进行功能分区, 创建多样的生境, 以实现不同的保 护功能。如在衍璚类的保护区域内增大养殖塘面 积, 增加水位梯度变化管理; 在雁鸭类保护区域内 注重增加芦苇群落面积和斑块数。(2)增加东滩围剭 区域土地利用和管理运作的多样性, 尤其应加快以 生态保护和宣教为目的的水禽湖、湿地公园等项目 建设，以便在私人养殖塘进行冬季清塘期间，仍能

\section{参考文献:}

Chen KL. 1995. An introduction to Ramsar convention[J]. Chinese Biodiversiy, 3(2):119-121.[陈克林. 1995.《拉姆萨尔公约》—《湿 地公约》介绍. 生物多样性, 3(2): 119-121.]

Dang AR. Wang XD. Chen XF. Zhang JB. 2003. Erdas Imagine[M]. Beijing: Tsinghua University Press. [党安荣, 王晓栋, 陈晓峰, 张 建宝. 2003. Erdas Imagine 遥感图像处理方法. 北京: 清华大学出 版社.]

Gao Y, Zhao B. 2006. The effect of reclamation on mud flat development in Chongming Island, Shanghai [J]. Chinese Agricultural Science Bulletin, 22(8): 475-479. [高 宇, 赵 斌. 2006. 人类围虎活动对上 海崇明东滩滩涂发育的影响. 中国农学通报, 22(8): 475-479.]

Ge ZM, Wang TH, Zhou X, Zhao P, Shi WY. 2006. Factor analysis on habitat selection of the avian community at the artificial wetlands behind the Chongming Dongtan seawall during winter and spring [J]. Zool Res, 27(2): 144-150. [暮振鸣, 王天厚, 周 晓, 赵 平, 施 文或. 2006. 上海崇明东滩堤内次生人工湿地鸟类冬春季生境选择 的因子分析, 动物学研究, 27(2): 144-150]

Huang HM, Zhang LQ, Gao ZG. 2005. The vegetation resource at the intertidal zone in Shanghai using remote sensing [J]. Acta Ecological Snica, 25(10): 2686-2693. [黄华梅, 张利权, 高占国. 2005. 上海滩 涂植被资源遥感分析. 生态学报, 25(10): 2686-2693.]

Liu H. 2006. Effect of Man-made Wetlands on the Conservation of Waterbirds [D]. Ph.D.thesis, East China Normal University, Shanghai.刘 吴. 2006. 人工湿地生境在水鸟保护中的作用研究. 上海: 华东师范大学博士学位论文.]

Minton RS. 1982. Report on wader expedition to north west Australia in August/ September 1981[J]. Stilt, 2: 14-26.

Monica GT. 2006. Landscape ecology: What is the state of the Science?[J]. Chinese Journal of Ecology, 25 (7): 834-844. [Monica GT. 2006. 景 观生态学发展现状. 生态学杂志, 25 (7): 834-844.]

Samuel KR, Brian EK, Thomas MB. 2003. Birds in north American Great Lakes coastal wet meadows: Is Landscape context important [J]. Landscape Ecology, 18: 95-111.

Shanghai Agriculture and Forestry Administration. 2004. The Terraneous Wildlife Resources of Shanghai [M]. Shanghai: Scientific \& Technical Publishers. [上海市农林局. 2004. 上海陆生野生动植物资源. 上海: 上海科学技术出版社.]

Sun RY. 2001. Principles of Animal Ecology. Third Edition[M]. Beijing: Beijing Normal University Press. [孙儒泳. 2001. 动物生态学原理,
为越冬水鸟提供持续、稳定的栖息场所。(3)应在更 大的尺度上探讨崇明东滩养殖塘景观特征对越冬 水鸟群落分布的影响。区域和尺度的增大可以增加 景观内的斑块类型和复杂性, 有利于探讨人工湿地 景观背景中自然湿地因素的作用，这对于深刻认识 自然湿地及其丧失对人工湿地中水鸟群落的影响 很重要。

第三版. 北京: 北京师范大学出版社.]

Sun ZH. Zhao RQ. 1996. Dynamic changes of migratory bird natural reserve in Chongming Eastern Beach [J]. Shanghai Environmental Sciences, 15(10): 41-44.[孙振华，赵仁泉. 1996. 崇明东滩候鸟自然 保护区的动态变化. 上海环境科学, 15 (10): 41-44.]

Wang JL, Chen Y. 2004. Applications of 3S technology in wildlife habitat researches [J]. Geography and Geo-Information Science, 20(6): 44-47. [王金亮, 陈 姚. 2004. 3S 技术在野生动物生境研究中的应用. 地 理与地理信息科学, 20 (6): 44-47.]

Wu L, Liu Y, Zhang J, Ma XJ, Wei ZY, Tian Y. 2001. Geographic Information System: Principles, Methods and Applications[M]. Beijing: Science Press. [乌邬 伦, 刘 瑜, 张晶, 马修军, 韦中亚, 田 原. 2001. 地理信息系统一原理、方法和应用. 北京: 科学出 版社.]

Wu JG. 2000. Landscape Ecology: Pattern, Process, Scale and Hierarchy[M] Beijing: Higher Education Press. [乌邭建国. 2000. 景观生态学: 格局、 过程、尺度和等级. 北京: 高等教育出版社.]

Xu L, Li B, Yuan X, Xu HF. 2006. The characteristics of the Avian community in Chongming Dongtan spring 2003[J]. Chinese Journal of Zoology, 41 (6): 120-126. [徐 玲, 李 波, 袁 晓, 徐宏发. 2006. 崇明东滩春季鸟类群落特征. 动物学杂志, 41 (6): 120-126.]

Xu JH. 2006. Quantity Geography[M]. Beijing: Higher Education Press. [徐 建华. 2006. 计量地理学. 北京:高等教育出版社.]

Yang YX. 2002. New knowledge on the progress of international wetland science research and priority field and prospect of Chinese wetland science research[J]. Advance in Earth Sciences, 17(4):508-514.[杨永 兴. 2002. 国际湿地科学研究进展和中国湿地科学研究优先领域与 展望. 地球科学进展, 17(4): 508-514.]

Ma ZJ. Li B. Zhao B. Jing K. Tang SM. Chen JK. 2004. Are artificial wetlands good alternatives to natural wetlands for waterbirds? - A case study on Chongming Island, China [J]. Biodiversity and Conservation, 13: 333-350.

Zhong YK, Zhou H, Shi WY, Zhou X, Zhou LC, Wang TH. 2006. Survey on shore birds community and their habitat in Shanghai tidal flat in spring[J]. Resources and Environment in the Yangtze Basin, 15 (3): 378-383. [仲阳康, 周 慧, 施文战, 周 晓, 周立晨, 王天厚. 2006. 上海滩涂春季鸭形目鸟类群落及围垦后生境选择. 长江流域资源 与环境, 15 (3):378-383.] 